DAMITZ, Caroline Vasconcelos; FARIA, Josiane Petry. A (oni)presença do poder na produção de subjetividades e na construção do imaginário social nas sociedades contemporâneas por análise da obra de Castor Ruiz. Revista Eletrônica Direito e Política, Programa de Pós-Graduação Stricto Sensu em Ciência Jurídica da UNIVALI, Itajaí, v.13, n.1, $1^{0}$ quadrimestre de 2018. Disponível em: www.univali.br/direitoepolitica - ISSN 1980-7791

\title{
A (ONI)PRESENÇA DO PODER: A TOLERÂNCIA NA PRODUÇÃO DE SUBJETIVIDADES E NO IMAGINÁRIO SOCIAL NAS SOCIEDADES CONTEMPORÂNEAS POR ANÁLISE DA OBRA DE CASTOR RUIZ
}

\author{
THE (OMNI)PRESENCE OF POWER: THE TOLERANCE IN THE PRODUCTION OF \\ SUBJETIVIES AND IN THE SOCIAL IMAGINARY IN CONTEMPORARY SOCIETIES \\ BY ANALYSIS OF CASTOR RUIZ'S WORK
}

Caroline Vasconcelos Damitz ${ }^{1}$

Josiane Petry Faria²

SUMÁRIO: Introdução; 1. A Onipresença do Poder; 2. A Produção de Subjetividades Flexíveis dos Indivíduos; 2.1 Símbolos que legitimaram o poder; 2.2 Ressignificação dos símbolos: uma visão semântica e de alteridade; 2.30 poder nas sociedades multiculturais; Considerações Finais; Referências das Fontes Citadas.

\begin{abstract}
RESUMO
Vive-se em uma sociedade plural, multicultural, complexa e contemporânea; de maneira que os sujeitos são a todo momento influenciados por símbolos que formam o imaginário social de sua comunidade contextualizado temporalmente. Onipresente a essa influência está o poder, que se exercita e legitima através de mecanismos que interferem na produção das subjetividades dos indivíduos, os tornando cooperantes com o sistema em todas as relações cotidianas. Nesse caminho, o objetivo do trabalho está em refletir quanto as questões relacionadas ao poder, concernentes à sua onipresença e ao diálogo com o Direito e o saber para entender criticamente os paradoxos daí decorrentes. Utiliza-se o método dedutivo e a técnica de pesquisa é a bibliográfica. Nesse estudo se desenvolve conceitos relativos ao patriarcalismo e às relações de poder e gênero.
\end{abstract}

Palavras-chave: Imaginário social; Poder; Produção de subjetividades

1 Mestra e graduada em Direito pela Universidade de Passo Fundo. Integrante do Grupo de Pesquisa Dimensões do Poder, Gênero e Diversidade certificado junto ao CNPQ. Bolsista voluntária do Projur Mulher e Diversidade. Advogada. carolinedamitz@gmail.com.

2 Doutora em Direito pela Universidade de Santa Cruz do Sul com bolsa Prosup e PDSE Capes na Universidade de Sevilla/ES. Possui Mestrado em Direitos Fundamentais e Relações de Trabalho pela Universidade de Caxias do Sul, Especialização em Ciência Política e Graduação em Direito pela Universidade Federal de Pelotas. Coordenadora do Projur Mulher, professora adjunta da Faculdade de Direito e do Programa de Mestrado em Direito da Universidade de Passo Fundo. Coordenadora do Grupo de Pesquisa Relações Sociais e Dimensões do Poder. Passo Fundo, Rio Grande do Sul, Brasil. Advogada. jfaria@upf.br. 
DAMITZ, Caroline Vasconcelos; FARIA, Josiane Petry. A (oni)presença do poder na produção de subjetividades e na construção do imaginário social nas sociedades contemporâneas por análise da obra de Castor Ruiz. Revista Eletrônica Direito e Política, Programa de Pós-Graduação Stricto Sensu em Ciência Jurídica da UNIVALI, Itajaí, v.13, n.1, $1^{0}$ quadrimestre de 2018. Disponível em: www.univali.br/direitoepolitica - ISSN 1980-7791

\section{ABSTRACT}

We live in a plural, multicultural, complex and modern society; so that its subjects are, at all times, influenced by symbols that form the social imaginary of their temporary contextualized community. Omnipresent to this influence it is power, which exercises and legitimates itself through mechanisms that interfere with the production of subjectivity on individuals, making them cooperative with the system in all ordinary relationships. In this way, the aim of this work is to reflect about the issues related to power, concerning its omnipresence and its dialogue with Law and the knowledge to critically understand the resulted paradoxes.

Keywords: Power; Production of subjectivity; Social imaginary

\section{INTRODUÇÃO}

O poder é onipresente na produção de subjetividades dos indivíduos e na construção do imaginário social das sociedades contemporâneas. A atualidade do tema é tamanha que uma gama de dúvidas se insurge no estudo, dessa forma, o presente artigo busca tecer considerações acerca da sociedade hodierna, complexa, interligada com um universo de culturas e crenças. Este texto é uma tentativa de reunir as lições aprendidas na leitura do texto "O (ab)uso da tolerância na produção de subjetividades flexíveis", do filósofo Castor M. M. Ruiz. Toda sociedade, independentemente de suas características, é formada por indivíduos que coexistem e convivem gerando infindáveis ramificações de relações de poder entre si.

Cada sociedade esteve, está e estará inserida em um contexto social, cultural, político, religioso e filosófico temporalmente, de modo que a cada geração de pessoas, a história da humanidade é construída. Para tanto, historicamente pode-se verificar alguns dos pontos fulcrais (símbolos) que denotam o imaginário social vigente. Nessa senda, o imaginário social é formado por símbolos utilizados a fim de legitimar o poder. Cada grupo cultural tem seus indivíduos formados por influências, nesse caso, as pessoas e/ou instituições que detém o monopólio dos mecanismos de poder, tem como consequência correlata o poder de produzir as subjetividades desses indivíduos, tornando-os cooperantes voluntária e tacitamente com seus interesses. 
DAMITZ, Caroline Vasconcelos; FARIA, Josiane Petry. A (oni)presença do poder na produção de subjetividades e na construção do imaginário social nas sociedades contemporâneas por análise da obra de Castor Ruiz. Revista Eletrônica Direito e Política, Programa de Pós-Graduação Stricto Sensu em Ciência Jurídica da UNIVALI, Itajaí, v.13, n.1, $1^{0}$ quadrimestre de 2018. Disponível em: www.univali.br/direitoepolitica - ISSN 1980-7791

Somente a mudança estrutural no imaginário social é que possibilita que esses indivíduos passem a questionar as regras estabelecidas pela Igreja, pelo Estado, pelas diretrizes de mercado etc., e em quaisquer dessas demandas aludidas, está de forma onipresente e mesmo onisciente, o poder.

\section{A ONIPRESENÇA DO PODER}

O poder é natural e histórico. E também é inevitável, uma vez que onde há interação humana há poder, eis que está presente no intercâmbio de influências entre as pessoas. O poder enquanto "coisa" não existe, para tanto, pode-se dizer que este é um fenômeno. Sua essência é circular nesses intercâmbios. "O poder é a sombra de nossa prática e a luz de nossas criações." ${ }^{3}$

O ser humano se relaciona estranhamente com o poder, haja vista que o instaurou e padece com ele, o teme e o necessita, se mantém submisso e quer dele se livrar ${ }^{4}$. O poder se manifesta de inúmeras maneiras: através da persuasão, da coação, da ameaça, da força, da resistência, da manipulação etc., ou seja, o poder é plurifacético. Também o é multidimensional em função de seus vários campos de atuação, além dos processos de tomada de decisão, atinge o de identificação de demandas e de discussão, e a execução de decisões. ${ }^{5}$

A própria tentativa de descrevê-lo, conceituá-lo é um exercício de poder, a tentativa do convencimento. As relações de poder podem ser multidirecionadas, mesclam amor e temor ${ }^{6}$. Maquiavel ${ }^{7}$, ao aconselhar o príncipe afirmou que, uma vez não sendo possível ser amado e temido ao mesmo tempo, deveria optar por

${ }^{3}$ RUIZ, Castor M. M. Bartolomé. Os labirintos do poder: O poder (do) simbólico e os modos de subjetivação. Porto Alegre: Escritos, 2004, p. 09.

4 FARIA, Josiane Petry. A democratização da inovação tecnológica, para além de manifestação de poder: o amor como cuidado núcleo de valores de políticas públicas para o desenvolvimento como liberdade. Tese (Doutorado em Direito). Faculdade de Direito. UNISC. Santa Cruz do Sul, 2014, p. 24.

${ }^{5}$ SORIANO, Rámon. Sociología del Derecho. Barcelona: Editorial Ariel, 1997, p. 319

6 FARIA, Josiane Petry. A democratização da inovação tecnológica, para além de manifestação de poder: o amor como cuidado núcleo de valores de políticas públicas para o desenvolvimento como liberdade. Tese (Doutorado em Direito). Faculdade de Direito. UNISC. Santa Cruz do Sul, 2014, p. 26.

7 MAQUIAVEL, Nicolau. O príncipe. São Paulo: Penguin e Companhia das Letras. 2000, p. 108 
DAMITZ, Caroline Vasconcelos; FARIA, Josiane Petry. A (oni)presença do poder na produção de subjetividades e na construção do imaginário social nas sociedades contemporâneas por análise da obra de Castor Ruiz. Revista Eletrônica Direito e Política, Programa de Pós-Graduação Stricto Sensu em Ciência Jurídica da UNIVALI, Itajaí, v.13, n.1, $1^{0}$ quadrimestre de 2018. Disponível em: www.univali.br/direitoepolitica - ISSN 1980-7791

ser temido, - pois as pessoas provocam mal a quem amam, não o fazendo com quem temem.

As relações de dominação e submissão são onipresentes à existência humana, pois é sua razão de ser/existência reside o poder. Ruiz ${ }^{8}$ acrescenta que o poder é um símbolo: É um símbolo porque através dessa palavra conotamos um conjunto de sentidos, porque nunca conseguimos explicá-lo de maneira depleted (exaurida), essa simbologia indica que o poder não permite conceituações reducionistas. O poder "não é bom nem mau, apenas é. Sendo assim, permeável a toda conduta humana é fonte de criatividade, desejo e modificação, como também de dominação, sujeição e exploração" ${ }^{9}$.

Foucault ${ }^{10}$, dissera que não se tematiza o poder, uma vez que, toda teoria é transitória. É uma prática social construída historicamente. Nesse ínterim tornase possível vislumbrar que de fato o poder circula por todos os tipos e níveis de relações; portanto, impensável seria a tentativa de discorrer sobre todas elas, eis que são incontáveis e limitadas à razão humana, assim sendo, falar-se-á sobre a relação entre poder e Estado, no interior das relações familiares e o mercado.

O Estado representa a máxima personificação do poder, nele se pode localizar uma vasta gama de recursos, como o monopólio da força, o dinheiro público, a capacidade para ditar as regras do jogo, apoio de grandes organizações, forças armadas, sistema de educação e saúde, burocracia e fazenda pública. Todos esses recursos e poderosos instrumentos de legitimação estão à disposição dos governantes ${ }^{11}$. Nesse universo, a democracia é, até o momento, a melhor forma

${ }^{8}$ RUIZ, Castor M. M. Bartolomé. Os labirintos do poder: O poder (do) simbólico e os modos de subjetivação. Porto Alegre: Escritos, 2004, p. 10.

9 FARIA, Josiane Petry. A democratização da inovação tecnológica, para além de manifestação de poder: o amor como cuidado núcleo de valores de políticas públicas para o desenvolvimento como liberdade.

10 FOUCAULT, Michel. Microfísica do poder. Tradução de Roberto Machado. São Paulo: Graal, 2012, p. 103

11 MARINA, José Antonio. Teoria da inteligência criadora. São Paulo: Guarda Chuva. Tradução Antonio Fernando Borges, 2009. 
DAMITZ, Caroline Vasconcelos; FARIA, Josiane Petry. A (oni)presença do poder na produção de subjetividades e na construção do imaginário social nas sociedades contemporâneas por análise da obra de Castor Ruiz. Revista Eletrônica Direito e Política, Programa de Pós-Graduação Stricto Sensu em Ciência Jurídica da UNIVALI, Itajaí, v.13, n.1, $1^{0}$ quadrimestre de 2018. Disponível em: www.univali.br/direitoepolitica - ISSN 1980-7791

de gerir todo esse poderio. Nela se abre um campo de empoderamento do cidadão, maior alternância e distribuição de poder ${ }^{12}$.

Entre os familiares, as relações de poder são muito variadas. Na família tradicional, o sistema rígido de obediência se baseava em três sistemas de legitimação: a natureza, a religião e o costume. A religião e a "lei natural" possuíam forte poder legitimador, pois a fonte era ficcional ${ }^{13}$. Por outro lado, 0 mercado se mostra como uma forte estrutura de poder, influindo na vida de todos, pois detém a maioria dos instrumentos de trabalho e determina a oferta de bens, sendo o capital um acumulado de recursos que amplia as possibilidades de ação, produção e, portanto, de mando e decisão. Aqui entram em ação elementos como: organização e liderança.

Destarte, baseado no exposto, vê-se em linhas gerais onde reside as figuras com "maior" poderio no mundo hodierno, desse modo, as ordens a nível de mundo (com o advento da globalização) devem ser políticas e articuladas interessadamente. E o são. Não obstante, o mercado para legitimar sua cultura de consumo, entra no terreno da ficção jurídica e constrói e repagina novos valores, pois na realidade é a ocupação, a possessão de um bem - e assim mantém a hegemonia do poder -. Essa é a força do mercado, o poder direto que funciona ao longo da história ${ }^{14}$.

Para Foucault, o poder não está localizado em nenhum ponto específico da cadeia social, pois é uma rede de mecanismos e tecnologias que a nada ou a ninguém escapa ${ }^{15}$. "Essa é a microfísica do poder, a sua permeabilidade a todos os espaços da existência humana e a todos, de modo que não existem pessoas

12 FARIA, Josiane Petry. A democratização da inovação tecnológica, para além de manifestação de poder: o amor como cuidado núcleo de valores de políticas públicas para o desenvolvimento como liberdade. Tese (Doutorado em Direito). Faculdade de Direito. UNISC. Santa Cruz do Sul, 2014.

13 MARINA, José Antonio. Teoria da inteligência criadora, p. 163.

14 MARINA, José Antonio. Teoria da inteligência criadora.

${ }^{15}$ FOUCAULT, Michel. Microfísica do poder, p. 112 
DAMITZ, Caroline Vasconcelos; FARIA, Josiane Petry. A (oni)presença do poder na produção de subjetividades e na construção do imaginário social nas sociedades contemporâneas por análise da obra de Castor Ruiz. Revista Eletrônica Direito e Política, Programa de Pós-Graduação Stricto Sensu em Ciência Jurídica da UNIVALI, Itajaí, v.13, n.1, $1^{0}$ quadrimestre de 2018. Disponível em: www.univali.br/direitoepolitica - ISSN 1980-7791

excluídas totalmente do poder"16, o poder atinge todas as relações, não necessariamente de modo homogêneo e equilibrado.

O poder alcança ao seu ponto mais abissal quando esta se prolonga no tempo, quando os mecanismos, símbolos, estratégias utilizadas adquirem eficiência, eficácia e aceitação a ponto de se prolongar no tempo. Nessa senda, o Direito regulamenta e legitima o poder. Quanto mais absoluto for o poder, mais este terá o Direito como instrumento a seu serviço e para a realização de seus fins. A máxima proximidade entre Direito e poder pode ser vislumbrada na medida em que ambos permeiam e perpassam pela legitimidade, ou seja, ambos possuem mecanismos que os legitimam.

Na formalização das relações de poder, o Direito ocupa papel de destaque, uma vez que, como uma prática social desenvolvida para a normatividade das condutas por meio da legislação, opera na normalização, com procedimentos e técnicas de normalização. Ao passo que existe uma norma, a partir dela é determinado o que seria o normal e o anormal. Ao mesmo tempo, o Direito, em sua vertente não legislativa possibilita a interpretação genealógica como discurso crítico. O Direito, assim como o poder, é uma realidade transacional, resultante de relações de forças inscritas em normas e instituições ${ }^{17}$.

Inserindo-se no contexto em que os direitos humanos surgiram na modernidade, ou seja, considerando a necessidade de mudança frente aos problemas do poder, da dominação e da exclusão social, pode-se compreender a tradução dos direitos humanos para a estrutura de institucionalização e reconhecimento normativo era necessário, o que findou por representar um esquecimento do caráter sóciohistórico desses direitos e ocasionar na intensificação da separação da teoria e prática, priorizando as violações em detrimento da efetivação dos mesmos.

16 FARIA, Josiane Petry. A democratização da inovação tecnológica, para além de manifestação de poder: o amor como cuidado núcleo de valores de políticas públicas para o desenvolvimento como liberdade, p. 30.

17 FARIA, Josiane Petry. A democratização da inovação tecnológica, para além de manifestação de poder: o amor como cuidado núcleo de valores de políticas públicas para o desenvolvimento como liberdade, p. 29. 
DAMITZ, Caroline Vasconcelos; FARIA, Josiane Petry. A (oni)presença do poder na produção de subjetividades e na construção do imaginário social nas sociedades contemporâneas por análise da obra de Castor Ruiz. Revista Eletrônica Direito e Política, Programa de Pós-Graduação Stricto Sensu em Ciência Jurídica da UNIVALI, Itajaí, v.13, n.1, $1^{0}$ quadrimestre de 2018. Disponível em: www.univali.br/direitoepolitica - ISSN 1980-7791

Dito isso, a onipresença do poder nas suas dimensões é capaz de fazer com que o saber seja compartido e que a gestão do conhecimento objetive desígnios comuns, criando-se ambientes de empoderamento. ${ }^{18} \mathrm{O}$ poder está presente nos símbolos vigentes de uma época, nos valores imperiosos de determinada cultura, ele está presente nas normas de conduta coercitivas e morais de uma sociedade, na doutrina das religiões, na produção de subjetividades flexíveis ${ }^{19}$, na mídia, na globalização, na guerra, na paz e mesmo no amor.

\section{A PRODUÇÃo DE SUBJETIVIDADES FLEXÍVEIS DOS INDIVÍDUOS}

A identidade trama o modo de ser do sujeito e a sua constituição é um campo de poder acirradamente disputado. Disputa essa que se tornou sinuosa nas sociedades contemporâneas, onde os mecanismos de poder se consolidam pela integração cooperante dos indivíduos prescritivos do sistema. Os sistemas das sociedades contemporâneas modelaram subjetividades flexíveis, produzidas pelo adestramento do indivíduo que, no seu processo identitário, se autoafirma à medida que se adapta funcionalmente aos imperativos requeridos pelas instituições.

Para Ruiz $^{20}$, as identidades do indivíduo e do sujeito se diferem, enquanto o indivíduo se sujeita flexivelmente aos referenciais externos elaborados pelo modelo social que configura sua identidade e adapta sua prática aos objetivos do sistema, sem questionar ou refletir sobre o imposto, o sujeito, por sua vez, constrói seus próprios referenciais - igualmente simbólicos- para se auto-definir como pessoa, o que Ihe possibilita direcionar sua prática de modo autônomo.

O autor entende que essa diferenciação no conceito de indivíduo e sujeito é importante, eis que o "objetivo", o caminho natural de todo indivíduo é tornar-se sujeito e, dessa forma, não moldar-se de forma absoluta ao poder legitimado

18 FARIA, Josiane Petry. A democratização da inovação tecnológica, para além de manifestação de poder: o amor como cuidado núcleo de valores de políticas públicas para o desenvolvimento como liberdade.

19 RUIZ, Castor M. M. Bartolomé. O (ab)uso da tolerância na produção das subjetividades flexíveis. In: SIDEKUM, Antônio. (Org). Alteridade e multiculturalismo. Ijuí: Ed. Unijuí, 2003.

20 RUIZ, Castor M. M. Bartolomé. O (ab)uso da tolerância na produção das subjetividades flexíveis. In: SIDEKUM, Antônio. (Org). Alteridade e multiculturalismo, 2003. 
DAMITZ, Caroline Vasconcelos; FARIA, Josiane Petry. A (oni)presença do poder na produção de subjetividades e na construção do imaginário social nas sociedades contemporâneas por análise da obra de Castor Ruiz. Revista Eletrônica Direito e Política, Programa de Pós-Graduação Stricto Sensu em Ciência Jurídica da UNIVALI, Itajaí, v.13, n.1, $1^{0}$ quadrimestre de 2018. Disponível em: www.univali.br/direitoepolitica - ISSN 1980-7791

pelos símbolos vigentes no imaginário social de sua época. O indivíduo é livre para escolher entre uma diversidade de opções postas para ele, mas não por ele. O sujeito cria sua opção de ser pessoa e seu modo de entender a sociedade.

É por meio de elementos simbólicos que a identidade se cria, desenvolve e se consolida; ela se trama na interação do sujeito com a realidade. Ou seja, o sujeito só existe a partir do momento em que constrói sua autoconsciência de sujeito, sua identidade. Os mecanismos de poder contemporâneos desenvolveram formas de identidade (simbólicas) que tem como objetivo básico a identificação dos indivíduos com os princípios programáticos do sistema que privilegiam a dimensão econômica.

\subsection{SÍMBOLOS QUE LEGITIMARAM O PODER}

Em uma sintetizada retrospectiva, a honra fora um dos elementos simbólicos centrais que interagiu com o poder, nas sociedades tradicionais, diversamente das contemporâneas, a honra é um núcleo articulador, é um valor-chave e diz muito sobre o comportamento da época ${ }^{21}$. Tem como princípio a desigualdade natural das pessoas e a correspondente estratificação da sociedade. Para que uns tenham honra, outros não podem tê-la, os que carecem de honra devem obediência e respeito àqueles que a tem ${ }^{22}$.

A honra é hereditária ao sobrenome e classe social desta ou daquela família. A relação de honra sela-se no pacto da vassalagem ${ }^{23}$, os indivíduos aceitam a estratificação por estamentos como algo natural e incontestável. Para entendermos o símbolo que sucedeu ao da honra, é preciso saber que se muda o status quo de uma sociedade, construindo novas formas simbólicas de aceitação

\footnotetext{
21 RUIZ, Castor M. M. Bartolomé. O (ab)uso da tolerância na produção das subjetividades flexíveis. In: SIDEKUM, Antônio. (Org). Alteridade e multiculturalismo, 2003.

22 RUIZ, Castor M. M. Bartolomé. O (ab)uso da tolerância na produção das subjetividades flexíveis. In: SIDEKUM, Antônio. (Org). Alteridade e multiculturalismo, 2003, p. 119.

${ }^{23}$ RUIZ, Castor M. M. Bartolomé. O (ab)uso da tolerância na produção das subjetividades flexíveis. In: SIDEKUM, Antônio. (Org). Alteridade e multiculturalismo, 2003, p. 120.
} 
DAMITZ, Caroline Vasconcelos; FARIA, Josiane Petry. A (oni)presença do poder na produção de subjetividades e na construção do imaginário social nas sociedades contemporâneas por análise da obra de Castor Ruiz. Revista Eletrônica Direito e Política, Programa de Pós-Graduação Stricto Sensu em Ciência Jurídica da UNIVALI, Itajaí, v.13, n.1, $1^{0}$ quadrimestre de 2018. Disponível em: www.univali.br/direitoepolitica - ISSN 1980-7791

social, ou seja é necessário instituir um novo imaginário social, um novo universo de simbolismos que trouxesse novos valores às instituições e à sociedade ${ }^{24}$.

No interregno entre os séculos XVII e XIX, o cenário era o de luta social e econômica, nesse contexto é que um novo símbolo foi instituído para substituir a honra, o novo símbolo fora a dignidade. O imaginário social e suas transformações não são ideias isoladas com força autônoma e independente, mas contextualizadas historicamente. ${ }^{25} \mathrm{O}$ símbolo do novo imaginário social é conferido de modo isonômico a todas as pessoas. A dignidade iguala a todos desde o nascimento. Ela legitima a igualdade natural de todos, é nesse símbolo nuclear que a identidade do indivíduo contemporâneo se estrutura.

O símbolo "dignidade" surgiu com diversos pensadores que influenciaram a modernidade. Figuras como Spinoza, Hobbes, Locke, Rousseau entre outros, coincidiram em afirmar a existência de um estado de natureza ${ }^{26}$. E que nesse estado de natureza todas as pessoas são iguais. O conceito se dá, ao seguir a linha de Hobbes ${ }^{27}$, que a igualdade do estado de natureza confere a todas as pessoas a mesma dignidade.

Hobbes defendia através do pacto social, que a dignidade fosse "transferida" ao soberano. Nessa senda, Locke diverge daquele. Locke vê a dignidade como algo inalienável, não podendo ser transferida a um soberano, já que ela corresponde ao indivíduo desde o nascimento. Entretanto, Locke foi um teórico da classe mercantilista inglesa, para ele a pessoa passa a ser definida, na sua dignidade, pela propriedade:

(...) daquilo que anteriormente expomos, podemos deduzir com clareza que, mesmo que nos foram dadas em comum todas as coisas da Natureza, o homem (dono e proprietário de si mesmo e

\footnotetext{
${ }^{24}$ RUIZ, Castor M. M. Bartolomé. O (ab)uso da tolerância na produção das subjetividades flexíveis. In: SIDEKUM, Antônio. (Org). Alteridade e multiculturalismo, 2003.

25 FARIA, Josiane Petry. A democratização da inovação tecnológica, para além de manifestação de poder: o amor como cuidado núcleo de valores de políticas públicas para o desenvolvimento como liberdade, p. 36.

${ }^{26}$ RUIZ, Castor M. M. Bartolomé. O (ab)uso da tolerância na produção das subjetividades flexíveis. In: SIDEKUM, Antônio. (Org). Alteridade e multiculturalismo. Ijuí: Ed. Unijuí, 2003.

27 HOBBES, Thomas. Leviatã ou matéria, forma e poder de um Estado eclesiástico e civil. Tradução de João Paulo Monteiro. São Paulo: Nova Cultura, 2000.
} 
DAMITZ, Caroline Vasconcelos; FARIA, Josiane Petry. A (oni)presença do poder na produção de subjetividades e na construção do imaginário social nas sociedades contemporâneas por análise da obra de Castor Ruiz. Revista Eletrônica Direito e Política, Programa de Pós-Graduação Stricto Sensu em Ciência Jurídica da UNIVALI, Itajaí, v.13, n.1, $1^{0}$ quadrimestre de 2018. Disponível em: www.univali.br/direitoepolitica - ISSN 1980-7791

sua pessoa, de seus atos ou do trabalho da mesma) portava dentro de si o grande fundamento da propriedade ${ }^{28}$.

A identidade da pessoa é dada pela sua potencialidade de ser proprietário. No que concerne às pessoas sem propriedade, Locke contesta ao dizer que todos somos proprietários por direito natural. A dignidade que Locke propugna está embrulhada num outro símbolo mais forte, a liberdade. A liberdade lockiana se estrutura como um mecanismo de sujeição dos indivíduos à nova forma de sociedade de classes que se hierarquiza entre proprietários (do capital) e trabalhadores.

A propriedade passa a ser o elemento constitutivo da identidade dos indivíduos; ser e ter se identificam -primórdios da visão do consumismo-. Rousseau trouxe uma voz dissonante dos discursos liberais que vinculam o estado de natureza com a propriedade privada.

O verdadeiro fundador da sociedade civil foi o primeiro que, tendo cercado um terreno, lembrou-se de dizer isto é meu e encontrou pessoas suficientemente simples para acredita-lo. Quantos crimes, guerras, assassínios, misérias e horrores não pouparia ao gênero humano aquele que, arrancando as estacas ou enchendo o fosso, tivesse gritado a seus semelhantes: "Defendei-vos de ouvir esse impostor; estareis perdidos se esquecerdes que os frutos são de todos e que a terra não pertence a ninguém ${ }^{29}$ !

Ele constata o formalismo (vazio) da dignidade liberal e contrapõe o simbolismo da dignidade liberal com os resultados de dignidade social que ela provoca. Identidade versus propriedade é a marca registrada das sociedades contemporâneas.

O objetivo das elites sociais contemporâneas consiste em conferir à dignidade um sentido que possibilite compatibilizar a sensação individual de liberdade com a aceitação cooperante de um projeto racional pré-definido. Interessa criar subjetividades flexíveis sujeitadas ao modelo social definido e evitar a criação de

28 LOCKE, John. Dois tratados sobre o governo. São Paulo: Martins Fontes. Tradução Julio Fischer, 1987, cap. V, par. 44

29 ROUSSEAU, Jean-Jacques. Discurso sobre a origem e os fundamentos da desigualdade entre os homens. Tradução de Lourdes Santos Machado. São Paulo: Abril Cultural, 1983, p. 259 
DAMITZ, Caroline Vasconcelos; FARIA, Josiane Petry. A (oni)presença do poder na produção de subjetividades e na construção do imaginário social nas sociedades contemporâneas por análise da obra de Castor Ruiz. Revista Eletrônica Direito e Política, Programa de Pós-Graduação Stricto Sensu em Ciência Jurídica da UNIVALI, Itajaí, v.13, n.1, $1^{0}$ quadrimestre de 2018. Disponível em: www.univali.br/direitoepolitica - ISSN 1980-7791

sujeitos que, de uma forma ou outra, questionam e possam vir a desestruturar a ordem vigente.

A teoria liberal que a burguesia desenvolveu "construiu uma hermenêutica restritiva do simbolismo da dignidade. A compreensão restritiva da cidadania, adaptada aos interesses da nova classe dominante possibilitou o controle deste símbolo"30 na construção de um novo imaginário da modernidade. Em razão dessa apropriação-vinculação entre propriedade e dignidade, a identidade liberal do cidadão será construída com sérias restrições.

Desse modo, somente aqueles homens que possuíam uma quantidade de propriedades e pagavam seus impostos eram reconhecidos como cidadãos. A maioria restante das pessoas permaneciam como infracidadãos, mulheres, crianças, pessoas sem propriedade, escravos etc. e um pouco mais a frente, os estrangeiros.

Um dos meios pelos quais se legitima a propriedade privada dos bens é o trabalho (visão lockiana), talvez o trabalho seja o principal meio. Dito isso, esta vinculação -sempre simbólica- entre propriedade e trabalho possibilitou a criação de dois novos símbolos do imaginário capitalista: valor de uso e valor de troca. Esta ligação constitui a coluna vertebral de toda a teoria econômica liberal, pois a ela estão vinculados os conceitos de mercadoria e de lucro.

\subsection{RESSIGNIFICAÇÃO DOS SÍMBOLOS: UMA VISÃO SEMÂNTICA E DE ALTERIDADE}

A própria natureza paradoxal do simbolismo possibilita que ele seja usado para legitimar o poder instituído ou para deslegitimá-lo. A exemplo disso tem-se a doutrina de Marx, que usou o mesmo simbolismo (trabalho) para produzir uma ressignificação semântica fulcral. Defendendo que o lucro do capital se produz como fruto da exploração do trabalho ${ }^{31}$.

30 KYMLICKA, Will. Filosofia Política Contemporânea. Rio de Janeiro: Martins Editora, 2006.

31 RUIZ, Castor M. M. Bartolomé. O (ab)uso da tolerância na produção das subjetividades flexíveis. In: SIDEKUM, Antônio. (Org). Alteridade e multiculturalismo, 2003, p. 138-139. 
DAMITZ, Caroline Vasconcelos; FARIA, Josiane Petry. A (oni)presença do poder na produção de subjetividades e na construção do imaginário social nas sociedades contemporâneas por análise da obra de Castor Ruiz. Revista Eletrônica Direito e Política, Programa de Pós-Graduação Stricto Sensu em Ciência Jurídica da UNIVALI, Itajaí, v.13, n.1, $1^{0}$ quadrimestre de 2018. Disponível em: www.univali.br/direitoepolitica - ISSN 1980-7791

Para ele, o único que pode ser, legitimamente, o dono dos benefícios da produção é o trabalhador, porque é ele quem gera lucro. O conceito de maisvalia é o valor criado pelo trabalhador, mas apropriado pelo capitalista. ${ }^{32}$ Por essa razão, os grupos excluídos e as classes dominadas travaram sempre, de modo consciente ou não, uma disputa pela ressignificação desses símbolos.

Dessa luta de poder dos grupos excluídos aparece a pretensão de desconstruir a sujeição produzida pelas identidades adestradas e possibilitar a sua constituição como sujeitos históricos com capacidade crítica e prática para decidir seu próprio destino. ${ }^{33}$ Para ilustrar as principais desconstruções que um símbolo pode sofrer ao longo de imaginários sociais diferentes, tem-se o símbolo da dignidade que no decorrer dos anos teve pelo menos três momentos de ressignificação.

Desse modo, um primeiro momento de ressignificação se deu pela possibilidade dos negros produzirem novas identidades e práticas de sujeitos livres, dando início a seu processo de "inclusão" social através das lutas sociais abolicionistas. Em um segundo momento esse simbolismo foi contestado pelo movimento operário, a característica desse movimento é tramada a partir da identidade de classe e de direitos econômicos, a pessoa é aquilo que vive. Por fim, em um terceiro momento o simbolismo liberal da dignidade foi desconstruído através do movimento pela emancipação da mulher; ainda recorrente hodiernamente ${ }^{34}$.

\subsection{O PODER NAS SOCIEDADES MULTICULTURAIS}

Vive-se em meio a inúmeras sociedades, altamente complexas, onde as identidades se segmentaram e se entrecruzaram na configuração de uma mesma identidade. Qualquer forma de identidade seja ela de classe, religiosa, étnica, cultural, filosófica etc., que pretenda ser absoluta, será insuficiente para exercer seu papel de símbolo articulador do complexo conjunto de práticas sociais das sociedades atuais.

\footnotetext{
32 RUIZ, Castor M. M. Bartolomé. O (ab)uso da tolerância na produção das subjetividades flexíveis. In: SIDEKUM, Antônio. (Org). Alteridade e multiculturalismo, 2003, p. 139.

33 FOUCAULT, Michel. Estratégia, poder-saber. Tradução de Vera Lucia Avellar Ribeiro. Rio de Janeiro: Forense Universitária, 2012.
}

34 RUIZ, Castor M. M. Bartolomé. O (ab)uso da tolerância na produção das subjetividades flexíveis. In: SIDEKUM, Antônio. (Org). Alteridade e multiculturalismo, 2003. 
DAMITZ, Caroline Vasconcelos; FARIA, Josiane Petry. A (oni)presença do poder na produção de subjetividades e na construção do imaginário social nas sociedades contemporâneas por análise da obra de Castor Ruiz. Revista Eletrônica Direito e Política, Programa de Pós-Graduação Stricto Sensu em Ciência Jurídica da UNIVALI, Itajaí, v.13, n.1, $1^{0}$ quadrimestre de 2018. Disponível em: www.univali.br/direitoepolitica - ISSN 1980-7791

Essa crise de identidades absolutas levou à expansão de uma nova forma de segmentação social que promove a construção de identidades plurais. Essas identidades convivem em sociedade e são desafiadas a coexistir na tensão da diferença. Entretanto, esse multiculturalismo não pode ocultar a principal contradição social, os interesses de classe -os socialmente excluídos e politicamente dominados-, assunto por demasiado complexo, devendo ser estudado em uma pesquisa à parte.

Ainda assim cabe referir, que as elites sociais investem na criação de novos símbolos que produzam um tipo de sujeição cooperante dos indivíduos ${ }^{35}$; essa sujeição se efetiva à medida que os indivíduos se identificam com o universo simbólico do sistema social e o internalizam como sendo seu próprio desejo.

A multiplicidade cultural, que talvez esteja no seu ápice, uma vez que, nunca se viu tantas culturas, religiões e personalidades tão interconectadas e acessíveis (produto da modernidade e da globalização), torna-se, sob esta perspectiva, u modo absoluto de relativizar o outro. É pouco aceitável consentir um princípio "universal" que sirva de critério definitivo para uma crítica social e cultural. A última tentativa de formulação de um princípio universal foi proposta pela Modernidade: a razão, mas ela tem, também, uma face perversa que arquiteta formas de dominação e maneiras de exclusão social.

Dessa forma, o que se propõe como melhor resposta a esse dilema, na opinião do professor Castor Ruiz ${ }^{36}$ é a alteridade do outro e do mundo da vida. Essa alteridade é um critério universalizável e relativo, que compagina o paradoxo de penetrar em todas as sociedades. A alteridade oferece critérios que possibilitam construir modos e modelos abertos de valores, princípios e práticas, critérios para desenvolvermos nosso universo de significações e direcionar práticas.

O indivíduo alienado pela subjetividade cooperante com o sistema sente-se questionado pelo sofrimento do outro. É o começo da desconstrução do indivíduo

\footnotetext{
35 RUIZ, Castor M. M. Bartolomé. O (ab)uso da tolerância na produção das subjetividades flexíveis. In: SIDEKUM, Antônio. (Org). Alteridade e multiculturalismo, 2003.

36 RUIZ, Castor M. M. Bartolomé. O (ab)uso da tolerância na produção das subjetividades flexíveis. In: SIDEKUM, Antônio. (Org). Alteridade e multiculturalismo, 2003.
} 
DAMITZ, Caroline Vasconcelos; FARIA, Josiane Petry. A (oni)presença do poder na produção de subjetividades e na construção do imaginário social nas sociedades contemporâneas por análise da obra de Castor Ruiz. Revista Eletrônica Direito e Política, Programa de Pós-Graduação Stricto Sensu em Ciência Jurídica da UNIVALI, Itajaí, v.13, n.1, $1^{0}$ quadrimestre de 2018. Disponível em: www.univali.br/direitoepolitica - ISSN 1980-7791

e o início do nascimento de um possível sujeito. A justiça remete à responsabilidade e ao compromisso com o outro e exige que estruturas sociais se transformem em instrumentos a serviço dessa pessoa e da vida. Na tarefa de nos constituirmos sujeitos históricos e de nos desvencilharmos dos modos de sujeição socialmente instituídos, devemos acolher a alteridade como critério de realização da própria subjetividade.

Nesse momento, válido retomar a figura do Direito, que em suas diferentes linguagens, atua fortemente nas relações de poder no paradoxo da subjetivação autônoma e da sujeição do indivíduo. Ao fornecer meios de entendimento e crítica, estimula o surgimento dos sujeitos autônomos. No entanto, ao pretender a sujeição dos indivíduos, transforma-se numa tecnologia de dominação que visa à submissão da pessoa por meio de sua subjetividade. Nas palavras de Ruiz:

(...) encontramo-nos na encruzilhada que, ao pensar os modos de subjetivação, tem que definir-se entre duas opções possíveis: a) a produção de dispositivos de subjetivação que estimulem a constituição de subjetividades autônomas, isto é, com capacidade para definir seu desejo, seu estilo de vida e o modelo de sociedade; b) pensar, pelo contrário, a criação de dispositivos de poder que visem à sujeição dos indivíduos de forma dócil e cooperativa às estruturas vigentes com o objetivo de conseguir o funcionamento mais eficiente possível das instituições com pretensão de dar estabilidade e produtividade ao sistema no seu conjunto ${ }^{37}$.

Trata-se de uma intervenção nas cadeias simbólicas que submetem à crítica, "mostrando o caráter histórico e relativo-perspectivo, e, por isso mesmo, põe em crise a relação dos sujeitos produtores, usuários e destinatários do Direito com a própria autonarração da ordem jurídica"38. Toda alteridade é relativa a uma identidade. Sem a configuração de novas identidades não é possível a constituição de novos sujeitos sociais. Tudo está culturalmente simbolizado. E se busca a dignidade como um fim. A sujeição (voluntária) dos indivíduos permite o

37 RUIZ, Castor M. M. Bartolomé. O (ab)uso da tolerância na produção das subjetividades flexíveis. In: SIDEKUM, Antônio. (Org). Alteridade e multiculturalismo, 2003, p. 16.

38 FARIA, Josiane Petry. A democratização da inovação tecnológica, para além de manifestação de poder: o amor como cuidado núcleo de valores de políticas públicas para o desenvolvimento como liberdade, p. 30. 
DAMITZ, Caroline Vasconcelos; FARIA, Josiane Petry. A (oni)presença do poder na produção de subjetividades e na construção do imaginário social nas sociedades contemporâneas por análise da obra de Castor Ruiz. Revista Eletrônica Direito e Política, Programa de Pós-Graduação Stricto Sensu em Ciência Jurídica da UNIVALI, Itajaí, v.13, n.1, $1^{0}$ quadrimestre de 2018. Disponível em: www.univali.br/direitoepolitica - ISSN 1980-7791

encobrimento dos mecanismos de poder, na medida em que se aceitam como formas naturais de inserção social.

\section{CONSIDERAÇÕES FINAIS}

Diante do exposto pode-se dizer que, de fato, o poder está presente em todas as searas da vida, como um Leviatã a observar os indivíduos cooperantes tentando se tornarem sujeitos passíveis e capazes de questionar o sistema e as desigualdades presentes a sua época.

O poder a todo tempo circula e não o faz de modo monopolizado estaticamente, ou seja, todas as pessoas são detentoras de poder em algum momento de suas vidas, mas não o deterão para sempre ou de forma constante durante sua existência.

Hoje, vivenciando a sociedade contemporânea, os indivíduos são influenciados pelos símbolos do mercado, do consumismo, da internet e de suas líquidas relações, entre outros, entretanto, são indivíduos apenas mais um dos manequins expostos na vitrine da história. Representarão para os futuros admiradores dessa vitrine, personagens que vivenciaram uma sociedade multicultural, complexa, agressiva, influenciados pela tecnologia a relativizar nossas relações humanas para com o outro.

Talvez as próprias gerações sejam conhecidas pelo resgate de alguns valores perdidos, por mais igualdade de oportunidades, por mais empatia uns com os outros. Bem como, as gerações da época medieval, hoje são vistos como barbados.

O que se quer dizer é que todos os conceitos são relativos e temporários, mas há algo não passível de conceituação ao mesmo tempo em que é onipresente, ou seja, o poder. E faz parte da natureza humana, que esses símbolos moldem as escolhas e o caminho em busca de conhecimento, felicidade e auto-aceitação. 
DAMITZ, Caroline Vasconcelos; FARIA, Josiane Petry. A (oni)presença do poder na produção de subjetividades e na construção do imaginário social nas sociedades contemporâneas por análise da obra de Castor Ruiz. Revista Eletrônica Direito e Política, Programa de Pós-Graduação Stricto Sensu em Ciência Jurídica da UNIVALI, Itajaí, v.13, n.1, $1^{\circ}$ quadrimestre de 2018. Disponível em: www.univali.br/direitoepolitica - ISSN 1980-7791

\section{REFERÊNCIAS DAS FONTES CITADAS}

FARIA, Josiane Petry. A democratização da inovação tecnológica, para além de manifestação de poder: o amor como cuidado núcleo de valores de políticas públicas para o desenvolvimento como liberdade. Tese (Doutorado em Direito). Faculdade de Direito. UNISC. Santa Cruz do Sul, 2014. p. 255.

FOUCAULT, Michel. Estratégia, poder-saber. Tradução de Vera Lucia Avellar Ribeiro. Rio de Janeiro: Forense Universitária, 2012.

FOUCAULT, Michel. Microfísica do poder. Tradução de Roberto Machado. São Paulo: Graal, 2012.

HOBBES, Thomas. Leviatã ou matéria, forma e poder de um Estado eclesiástico e civil. Tradução de João Paulo Monteiro. São Paulo: Nova Cultura, 2000.

LOCKE, John. Dois tratados sobre o governo. São Paulo: Martins Fontes. Tradução Julio Fischer, 1998.

KYMLICKA, Will. Filosofia Política Contemporânea. Rio de Janeiro: Martins Editora, 2006.

MARINA, José Antonio. Teoria da inteligência criadora. São Paulo: Guarda Chuva. Tradução Antonio Fernando Borges, 2009.

MAQUIAVEL, Nicolau. O príncipe. São Paulo: Penguin e Companhia das Letras, 2000.

ROUSSEAU, Jean-Jacques. Discurso sobre a origem e os fundamentos da desigualdade entre os homens. Tradução de Lourdes Santos Machado. São Paulo: Abril Cultural, 1983.

RUIZ, Castor M. M. Bartolomé. O (ab)uso da tolerância na produção das subjetividades flexíveis. In: SIDEKUM, Antônio. (Org). Alteridade e multiculturalismo. Ijuí: Ed. Unijuí, 2003. p.115-171. 
DAMITZ, Caroline Vasconcelos; FARIA, Josiane Petry. A (oni)presença do poder na produção de subjetividades e na construção do imaginário social nas sociedades contemporâneas por análise da obra de Castor Ruiz. Revista Eletrônica Direito e Política, Programa de Pós-Graduação Stricto Sensu em Ciência Jurídica da UNIVALI, Itajaí, v.13, n.1, $1^{0}$ quadrimestre de 2018. Disponível em: www.univali.br/direitoepolitica - ISSN 1980-7791

RUIZ, Castor M. M. Bartolomé. Os labirintos do poder: O poder (do) simbólico e os modos de subjetivação. Porto Alegre: Escritos, 2004.

SORIANO, Rámon. Sociología del Derecho. Barcelona: Editorial Ariel, 1997.

Submetido em: 10/11/2016

Aprovado em: 19/04/2017 